\title{
The Rod-and-Frame Effect as a Function of the Righting of the Frame
}

\author{
Joseph R. DiLorenzo and Irvin Rock \\ Institute for Cognitive Studies, Rutgers University
}

\begin{abstract}
Several experiments investigated the theory that there is a tendency to interpret the axes of a large tilted frame of reference as surrogates of the main axes of the environment. Therefore there is a tendency to perceive such a frame as either upright or as less tilted than it is-righting-and, accordingly, to perceive a vertical rod as tilted in the opposite direction-the rod-and-frame effect (RFE). A high correlation was found between righting and the RFE in all experiments. When a double frame apparatus was used, with the outer frame upright and the inner frame tilted, there was no consistent RFE. This condition eliminates any righting effect. When the outer frame was tilted and the inner one was upright, however, the RFE was induced, as was a correlated righting effect. All experiments were repeated with the subject's head tilted, thereby increasing the tendency toward righting of the frame. The result was a corresponding increase in the RFE. The RFE can thus be thought of as the solution to the problem of the rod's tilt given the perceived tilt of the frame.
\end{abstract}

In the classic rod-and-frame effect (RFE) as originally investigated by Asch and Witkin (1948a, 1948b) and Witkin and Asch (1948), a luminous rod surrounded by a tilted luminous frame in an otherwise dark room appeared to be deflected away from the true vertical such that observers instructed to set the rod to the apparent vertical erred in the direction of the frame's tilt. Wertheimer's concept of the frame of reference had been invoked in an attempt to explain this error in the perceived verticality of the rod (see Koffka, 1935). Investigators postulated that the tilted frame acted as a world surrogate that in turn determined the apparent visual axes of space. Thus, the RFE was thought to represent the dominance of vision over information derived from gravity.

More recent formulations of the problem have resulted from investigations into the

This research was supported in part by Research Grant MH 30865 from the National Institute of Mental Health to Rutgers University.

We wish to thank Eric Sigman for his help with an earlier version of this article.

Irvin Rock is now a member of the Program in Cognition at Rutgers University.

Requests for reprints should be sent to Irvin Rock, Department of Psychology, Rutgers University, New Brunswick, New Jersey 08903. possible role of induced ocular eye torsion (Goodenough, Sigman, Oltman, Rosso, \& Mertz, 1979; Hughes, 1973), induced head tilt (Ebenholtz \& Benzschawel, 1977; Sigman, Goodenough, \& Flannagan, 1978, 1979 ), and angular contrast (Beh, Wenderoth, \& Purcell, 1971; Gogel \& Newton, 1975; Goodenough, Oltman, Sigman, Rosso, \& Mertz, 1979; Wenderoth, 1974).

Induced ocular eye torsion would occur were the eyes to respond to a tilted frame by rotating in the direction of that frame's tilt. If this rotation of the eyes was not registered centrally, then the rod would be set in accord with the vertical meridian of the eye, which would be in the direction of the frame's tilt. This effect has been found to be very small, of the order of no more than $.5^{\circ}$ (Goodenough, Sigman, et al., 1979; Hughes, 1973), and can hardly account for the average RFE.

According to the induced head-tilt hypothesis, the head is felt to be tilted in a direction opposite to the tilt of the inducing frame. To compensate for this felt head tilt, the rod is set in the direction of the frame's tilt. Although agreeing that induced head (or body) tilt is theoretically relevant to the RFE, we feel that this effect itself requires consideration of how the frame is perceived. 
We will examine this issue more closely in the General Discussion section.

According to the angular contrast hypothesis, the angular relation between the rod and the sides of the frame most nearly parallel to it is overestimated, thereby resulting in the rod's phenomenal deflection away from the frame. Since the rod would thus be perceived as tilted in a direction opposite to the tilt of the frame, it would consequently be adjusted in the direction of the frame's tilt by an observer asked to set it to the apparent vertical. This hypothesis has more commonly been used as explanation of certain geometrical illusions in which it is said that acute angles tend to be overestimated. The mechanism postulated as underlying angular contrast effects is an extension of the idea of lateral inhibition to the perceived orientation of contours (Békésy, 1967; Blakemore, Carpenter, \& Georgeson, 1970; Carpenter \& Blakemore, 1973).

The amount of contrast in studies employing a rod or line within a tilted square that has been reported is typically small, ranging from as little as $1^{\circ}$ to as much as around $3^{\circ}$ (Beh et al., 1971; Goodenough, Oltman, et al., 1979; Wenderoth, 1974), and thus contrast can at most account for an obtained RFE of this order of magnitude. However, contrast cannot account for the much larger RFE that is more commonly obtained (around $6^{\circ}$ ). There is, however, a significant difference to be noted between the majority of these contrast studies and the more traditional studies on the RFE. Specifically, in the case of the former, the frame's visual angle is small $\left(10^{\circ}\right.$ and under), whereas in the latter, the frame's visual angle is large $\left(28^{\circ}\right)$. Now it has been reported that the size of the visual angle subtended by the frame is critical to the size of the RFE obtained. In fact, a linear relationship has been demonstrated wherein the magnitude of the RFE has been shown to vary directly with the size of the frame's visual angle (Ebenholtz, 1977; Ebenholtz \& Callan, 1980). We may therefore surmise that angular contrast is more relevant to studies employing small-frame visual angles than to ones using large-frame visual angles. Thus we might be observing two quite distinct effects, one of which is partially ex- plainable in terms of angular contrast and the other of which is not. This indeed is the position taken in this article.

The following experiments are based on the postulate that a visual frame, if large enough, will tend to act as a representative or surrogate of the visual axes of space, and in so doing it will determine the perception of the vertical. There can be little question that such a process occurs when an observer is in a tilted structure such as a room, airplane, or ship (Witkin, 1949). In agreement with Wertheimer (see Koffka, 1935) and Asch and Witkin (1948a, 1948b; Witkin \& Asch, 1948), we hypothesized that the same kind of process occurs when the observer is outside of a visual structure-providing it is sufficiently large to serve as a surrogate of the environment. Under such conditions a conflict exists between this tendency of the visual frame to define the vertical (and horizontal) of space and information derived from gravity. Implicit in this view is the hypothesis that the RFE is the outcome of a tendency on the part of the visual system to accept a tilted frame of reference as upright or as less tilted phenomenally than it is objectively. We refer to this as the righting effect. We believe that the magnitude of the perceived underestimation of frame tilt will be equal to the size of the RFE obtained.

Contrary to this prediction, Gogel and Newton (1975) reported that their observers perceived the tilt of the frame veridically. To our knowledge, their study was the only one to include in its design a test of the perceived tilt of the frame. However, these results are not inconsistent with the hypothesis advanced here, since the visual angle of the frame used in the experiment was only $10^{\circ}$. That being the case, we would not expect the orientation of the frame to be underestimated; the frame is not large enough to serve as a surrogate of the environment.

The experiments reported here incorporate a measure of the perceived tilt of the frame. Preliminary investigation indicated that certain methods of determining the perceived orientation of the frame (such as one in which a rod was haptically adjusted until it was felt to be parallel to the experimental frame) were highly unreliable. We do not 
know why this method failed, since it was used successfully by Templeton (1972), Gogel and Newton (1975), and Goodenough, Oltman, et al. (1979). The difficulty seemed to stem from the large frames used in our experiments. Only Gogel and Newton used this method to measure perceived frame tilt, and their frame was quite small. The method of measurement we therefore employed was a derivative of that commonly used to measure the RFE. The frame was to be rotated toward the vertical until the observer indicated that it appeared to be upright. The presumption was that the observer would perceive the frame as upright in its initial starting position if he or she was subject to a complete righting effect and thus would accept it as upright in that position. Or the presumption was that he or she would adjust the frame in accordance with the amount of righting experienced when shown the frame in its tilted starting position. More carefully stated, it was presumed that if some degree of perceptual righting of the frame in its initially tilted position occurred in a given subject, the subject would accept the frame as upright in a tilted position when asked to set it to the vertical. The less tilted the frame appeared in its initial tilted position, the greater the tendency to accept it as upright in such a tilted position. Thus our measure of righting translates to a starting-position effect in the frame-adjustment task.

A preliminary experiment was designed to determine if the observer would in fact perceive a tilted frame as less tilted than it was. If so, this underestimation of frame tilt (or righting effect) was expected to be correlated with the RFE. An immediate test and a delayed test were used to determine what difference, if any, was to be found between the two methods. This was necessary because the delayed test was to be used in subsequent experiments to investigate the effect of head tilt upon both the RFE and frame-tilt underestimation. Head tilts have been found to increase reliance upon visual cues while diminishing the effectiveness of vestibular cues in conflict situations (Young, Oman, \& Dichgans, 1975). A delay period was incorporated because it was believed that adaptation to postural cues in the headtilt condition would increase visual dominance.
In the preliminary experiment, the visual angle of the frame was $32^{\circ}$, which, although greater than the $10^{\circ}$ used by Gogel and Newton (1975) and others, was not as great as in our main experiments. Following the same general procedure of our main experiments described below, no significant difference between immediate and delay conditions was obtained. Thus it was possible to use the delay condition exclusively in the main experiments without the concern that they would not be comparable to the more typically employed immediate condition. With the modest visual angle of the frame, the preliminary experiment yielded a mean RFE of $4.6^{\circ}$ and a mean righting effect of the frame of $4^{\circ}$ in the delay condition. The two measures were highly correlated.

\section{Experiment 1}

\section{Method}

Subjects. The observers were 12 graduate students of both sexes who were naive to the purpose of the experiment.

Apparatus. The standard RFE apparatus was used with a 40 -in. $(101.6 \mathrm{~cm})$ square frame that subtended a visual angle of $54^{\circ}$. The observer was seated in an erect position 39 in. $(99.1 \mathrm{~cm})$ from the frame. Both the rod and the frame were luminous and were the only objects visible in a completely dark room. (The rod and frame were made luminous by use of phosphorescent material. To prevent fading, a light was directed at the rod and frame immediately prior to each trial.) The observer was seated in a chair raised on a 6-in. (15.2 $\mathrm{cm}$ ) wooden platform, and the chair was fitted with an adjustable head clamp and chin rest with a circular aperture 8 in. $(20.3 \mathrm{~cm})$ in diameter that could be opened and closed by either the observer or the experimenter. The aperture was located directly in front of the observer's head at eye level. No edges of the aperture were visible to the observer. The adjustable head clamp was used to guarantee that the exact position of the observer's head would be maintained throughout the duration of the experiment.

Procedure. Outside the laboratory, the observer was shown a small replica of the rod-and-frame apparatus. The vertical was defined using the standard instructions by reference to familiar objects such as telephone poles, trees, or the straight edge formed by the intersection of two adjacent walls of a room. The observer then entered the laboratory and was seated. The RFE apparatus was presented first without the rod visible and with the frame set at a tilt of $20^{\circ}$ clockwise (cw) or counterclockwise (ccw).

Following a delay period during which the observer was exposed to the frame tilted by $20^{\circ} \mathrm{cw}$ or ccw for a period of $4 \mathrm{~min}$, the observer adjusted the frame alone to the apparent vertical. If in its starting position the frame was perceived as tilted, then the experimenter 
would move it slowly in $2^{\circ}$ steps in the direction indicated by the observer until it appeared to be vertical. This would comprise one frame-trial test. Next, the rod would be added at a position of $14^{\circ} \mathrm{cw}$ or $\mathrm{ccw}$ and the frame reset at its initial tilt of $20^{\circ} \mathrm{cw}$ or ccw. The observer was required to adjust the rod to the vertical using the same procedure already outlined for adjusting the frame to the vertical. This comprised one measure of the RFE. Each observer was given both the cw and ccw frame orientations, which were presented in separate blocks. The order of presentation of these frame-tilt blocks was counterbalanced both within and across observers. A total of four measurements were taken of the RFE and four of the righting effect.

\section{Results}

All of the scores reported represent the average of the signed deviations of either the rod or the frame from the vertical.

The data for ccw and cw frame tilts are summarized in Table 1 . The RFE was $11^{\circ}$ and $8.7^{\circ}$ for the ccw and cw frame tilts, respectively. This represents a significant increase from the effect obtained in the preliminary experiment. The mean scores for the righting effect were $7.7^{\circ}$ and $7.6^{\circ}$ for the ccw and cw conditions, respectively. These scores also represent a significant increase over the corresponding results of the preliminary experiment.

The RFE was positively correlated with the righting effect for both frame-tilt conditions: $r(10)=.58, p<.05$, and $r(10)=$ $.72, p<.01$, for each condition, respectively.

No statistically significant difference was found between the ccw and cw righting effects. However, the RFE was significantly different for these conditions, thereby preventing the combining of results from each.

\section{Discussion}

The use of a frame of a large visual angle resulted in a very substantial RFE of a magnitude not usually obtained in research on this problem since the early work of Witkin and Asch (1948). Moreover, the large RFE obtained was positively accompanied by a correspondingly large righting effect. Thus there is support for the contention that a large frame is more readily accepted as defining the visual axes of space, thereby allowing for a greater righting effect and a correspondingly larger RFE.
Table 1

Mean Deviation From the Vertical (in Degrees) for Experiments 1, 2, and 3 and the Subsidiary Experiments With Head Tilt

\begin{tabular}{|c|c|c|c|c|c|c|c|}
\hline \multirow{2}{*}{$\begin{array}{l}\text { Frame } \\
\text { orien- } \\
\text { tation }\end{array}$} & \multirow[b]{2}{*}{$n$} & \multicolumn{2}{|c|}{ Righting } & \multicolumn{2}{|c|}{$\begin{array}{l}\text { Inner } \\
\text { frame }\end{array}$} & \multicolumn{2}{|c|}{ RFE } \\
\hline & & $M$ & $S D$ & $M$ & $S D$ & $M$ & $S D$ \\
\hline \multicolumn{8}{|c|}{ Experiment 1} \\
\hline ccw & 12 & 7.7 & 3.1 & & & 11.0 & 3.4 \\
\hline cw & 12 & 7.6 & 4.4 & & & 8.7 & 5.4 \\
\hline \multicolumn{8}{|c|}{ Subsidiary experiment (head tilted) } \\
\hline ccw & 12 & 13.2 & 4.8 & & & 11.6 & 3.4 \\
\hline $\mathrm{cw}$ & 12 & 15.1 & 2.6 & & & 15.5 & 2.7 \\
\hline
\end{tabular}

Experiment 2 (double frame, outer frame upright)

\begin{tabular}{llllllll} 
ccw & 10 & 0 & 0 & .8 & .6 & 1.0 & 1.2 \\
cw & 10 & .1 & .3 & .1 & .5 & $-.2^{a}$ & 1.4 \\
& \multicolumn{8}{c}{$\begin{array}{l}\text { Subsidiary } \\
\text { ccw }\end{array}$} & 10 & 0 & 0 & 1.4 & 1.4 & .6 & 1.6 \\
cw & 10 & .2 & .8 & .5 & 1.5 & 2.2 & 2.8 \\
\hline
\end{tabular}

Experiment 3 (double frame, inner frame upright)

$\begin{array}{llllllll}\text { ccw } & 10 & 8.5 & 6.1 & 8.1 & 5.8 & 5.8 & 5.2 \\ \text { cw } & 10 & 8.1 & 3.6 & 9.4 & 5.7 & 5.8 & 4.6\end{array}$

Subsidiary Experiment (head tilted)

$\begin{array}{llllllll}\text { ccW } & 10 & 16.0 & 4.3 & 12.4 & 2.9 & 8.4 & 2.5\end{array}$

\begin{tabular}{llllllll} 
cw & 10 & 18.6 & 2.1 & 13.1 & 4.3 & 11.3 & 5.4 \\
\hline
\end{tabular}

Note. $\mathrm{cw}=$ clockwise; $\mathrm{ccw}=$ counterclockwise. RFE = rod-and-frame effect.

Minus sign indicates that the mean deviation of the rod was in a direction opposite to the tilt of the frame.

\section{Subsidiary Experiment With Head Tilted}

This experiment was repeated using 12 different observers of both sexes in an identical manner to Experiment 1 with one exception: Now the observer's head was tilted $45^{\circ} \mathrm{cw}$. Considerable care was taken to control for effects such as the A-effect (Aubert, 1861) and the E-effect (Müller, 1916), which are known to arise when the head or body is tilted. With head tilts of $60^{\circ}$ or more, the A-effect occurs, in which a single luminous upright rod will appear tilted in a direction opposite to the tilt of an observer's head. In order to accept the rod as phenomenally upright, therefore, the observer will adjust the rod in the direction of his or her head or body tilt. By tilting the frame to 
each side while keeping the head tilted in the same direction, the A-effect, if present, would be cancelled out. In one instance it would add to, and in the other instance it would subtract from, the overall error in adjusting the rod to the apparent vertical. However, as a further precaution, a $45^{\circ}$ head tilt was used, since it has been shown that little if any A-effect occurs at this particular tilt (Bauermeister, 1964, 1978) and little if any E-effect occurs (a constant error opposite in direction to the A-effect sometimes obtained for small head tilts). The results show that the RFE increased to $11.6^{\circ}$ in the $\mathrm{ccw}$ condition and to $15.5^{\circ}$ in the $\mathrm{cw}$ condition. However, only the latter increase was significant, $t(22)=3.9, p<.001$. The righting effect increased to $13.2^{\circ}$ and $15.1^{\circ}$ in the $\mathrm{ccw}$ and $\mathrm{cw}$ conditions, respectively. Both of these increases were significant, $t(22)=$ $3.32, p<.01$, and $t(22)=5.04, p<.01$, respectively (see Table 1). This suggests that by tilting the head by $45^{\circ}$ and thereby weakening the efficacy of available gravity cues, there is a greater tendency to accept the tilted frame as upright, or as less tilted than it is. This greater acceptance of the visual display as upright appears to result in a larger RFE.

\section{Experiment 2}

In induced movement, a stationary spot that is surrounded by a moving rectangular frame appears to move in a direction opposite to that of the frame. It is known that induced movement occurs even when the frame moves at rates well above the subjectrelative threshold. In this case, there is no logical necessity to attribute motion to the spot, since the relative motion between frame and spot can be veridically accounted for by the perception of motion of the rectangle alone. In order to explain induced movement in this instance, Duncker (1929/1950) proposed the principle of separation of systems. Movement of an object would be determined relative to its frame of reference only and is insulated from the effects of any frame of reference external to and beyond it. Thus, in induced movement the spot would appear to move relative to its frame of reference, the surrounding rectangle, and the rectangle

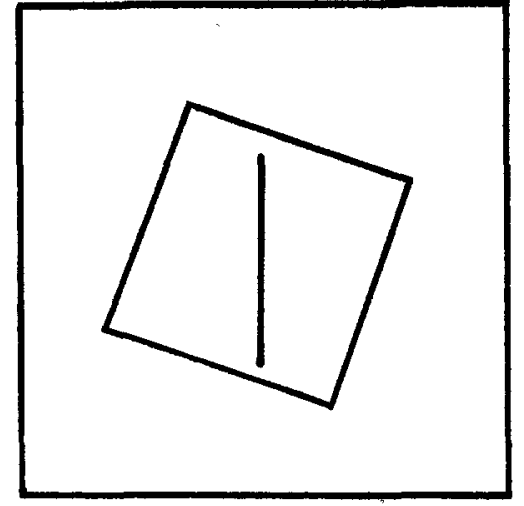

Figure 1. Double frame display used in Experiment 2 and in the subsidiary experiment with head tilt.

would appear to move relative to any other external frame of reference or to the observer.

The same principle could be applied to the RFE. The perceived orientation of the rod would be dependent upon the surrounding frame alone and would be independent of the perceived orientation of the frame. However, it is our belief that it is precisely the perceived orientation of the frame that is important, as the RFE is a function of the underestimation of that frame's tilt.

To test this hypothesis, a double frame and single rod apparatus was constructed. This allowed us to manipulate independently the tilt of an inner and an outer frame. We believe that when the outer frame is upright, any effect of a tilted inner frame upon the rod will be eliminated. This is contrary to the principle of separation of systems, according to which the tilted inner frame would influence the perceived orientation of the rod regardless of the presence of the outer frame.

\section{Method}

Subjects. The observers were 10 graduate students of both sexes who were naive as to the purpose of the experiment.

Apparatus. The modified RFE apparatus consisted of two luminous frames surrounding one luminous rod. The outermost frame was $40 \mathrm{in}$. $(101.6 \mathrm{~cm})$ square and had a visual angle of $54^{\circ}$. The inner frame was 24.75 in. $(62.9 \mathrm{~cm})$ square and had a visual angle of $32^{\circ}$. The observer was seated in the same aperture-chair apparatus used previously and was at a distance of 39 in. 
$(99.1 \mathrm{~cm})$ from the square frames, See Figure 1 for a representation of this experimental display.

Procedure. The outer frame was presented in an upright position and was exposed to the observer for a period of $4 \mathrm{~min}$. Following this exposure period, if the observer perceived the frame as tilted, it was adjusted to the apparent vertical by the experimenter, after which the frame was then returned to the objective vertical. Next, the inner frame was added to the outer frame at a tilt of $20^{\circ} \mathrm{cw}$ or ccw. The inner frame was now adjusted to the apparent vertical. Then the inner frame was returned to its initial tilted position. At this point the rod was added to the inner frame at a tilt of $14^{\circ}$ cw or ccw. The rod was then adjusted to the apparent vertical. Each observer was exposed to both the cw and ccw $20^{\circ}$ frame tilts, which were presented in separate blocks. The order of presentation of these frame-tilt blocks was counterbalanced both within and across observers. Four measurements were taken of the RFE and four of the apparent vertical of both the outer and inner frames.

\section{Results}

See Table 1 for a summary of the data. Essentially there was veridical perception of the outer frame, inner frame, and rod. The only effects that were significantly different from zero were those of the inner frame $\left(.8^{\circ}\right)$ and $\operatorname{rod}\left(1^{\circ}\right)$ in the ccw frame-tilt condition. However, these two variables were not significantly correlated, $r(8)=-.15$, $p>.05$.

\section{Discussion}

The fact that there is no consistent RFE of any appreciable magnitude under the given conditions of this experiment testifies to the relevance of the outer frame in determining the RFE. These results contradict the separation of systems principle, for it would predict that the effect of the tilted inner frame would result in an RFE quite independently of a surrounding outer frame.

\section{Subsidiary Experiment With Head Tilted}

This experiment was repeated using 10 different observers of both sexes in an identical manner to Experiment 2, with the exception that the observer's head was tilted $45^{\circ} \mathrm{cw}$. The same controls used in the previous head-tilt experiment were instituted. We reasoned that by investigating the RFE under conditions that are known to be more favorable for its induction, we would be better able to demonstrate the importance of the relevant frame of reference as a determinant of the RFE. Again there was no consistent RFE (see Table 1). Both the outer frame and the inner frame were perceived veridically, and there was no substantial rodand-frame effect. It appears that the upright outer square becomes such a powerful frame of reference that it inhibits any tendency of the tilted inner frame to affect the rod even given a situation normally known to be more conducive to the RFE.

\section{Experiment 3}

In this experiment the inner frame was now upright, whereas the outer frame was tilted. In this case we expected that the tilted outer frame would induce an illusion both in the inner frame and the rod. This effect would be in opposition to predictions based upon the principle of separation of systems.

\section{Method}

Subjects. The observers were 10 graduate students of both sexes who were naive to the purpose of the experiment.

Apparatus. The same double frame and single rod apparatus used in Experiment 2 was again used. The observer was seated in the same aperture-chair at the same distance from the frames. The visual angles of the frames were also the same as those in Experiment 2. See Figure 2 for a representation of this experimental display.

Procedure. The observer was exposed to the outer frame at a tilt of $20^{\circ} \mathrm{cw}$ or ccw for a period of $4 \mathrm{~min}$. Following this exposure period, the observer was required to adjust the frame to the vertical. The frame was then returned to its initial tilt, and the inner frame was added in the upright position. If the observer per-

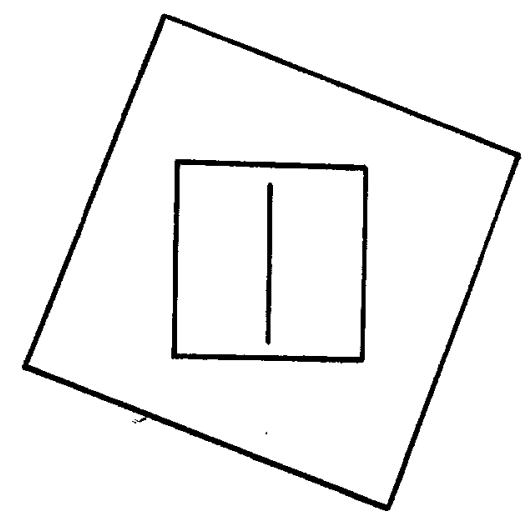

Figure 2. Double frame display used in Experiment 3 and in the subsidiary experiment with head tilt. 
Table 2

Mean Deviation From the Vertical (in Degrees) for a Rod in the Control Experiment: Rod Alone

\begin{tabular}{llrrrrr}
\hline & & \multicolumn{2}{c}{ Immediate } & & \multicolumn{2}{c}{ Delay } \\
\cline { 7 - 8 } $\begin{array}{l}\text { Orientation } \\
\text { of observer }\end{array}$ & $n$ & $M$ & $S D$ & & $M$ & $S D$ \\
\hline Erect & 10 & -.2 & .9 & & -.2 & 1.6 \\
Tilted & 10 & +1.6 & 2.9 & +.7 & 5.7 \\
\hline
\end{tabular}

Note. Minus sign indicates that the rod was tilted counter clockwise (ccw). Plus sign indicates that the rod was tilted clockwise (cw).

ceived the inner frame as tilted, it was then adjusted to the vertical. Next, the inner frame was reset to its initially vertical position, and the rod was added at a tilt of $14^{\circ} \mathrm{cw}$ or $\mathrm{ccw}$. The rod was then adjusted to the vertical. Each observer was exposed to both the cw and ccw frame tilts, which were presented in separate blocks. The order of presentation of these frame-tilt blocks was counterbalanced both within and across observers. Four measurements were taken of the RFE and of the apparent vertical of both the outer and inner frames.

\section{Results}

As can be seen in Table 1, the RFE was $5.8^{\circ}$ for both frame-tilt conditions. The righting of the outer frame was $8.5^{\circ}$ and $8.1^{\circ}$ for the ccw and $\mathrm{cw}$ conditions, respectively.

The correlations between the righting effect and the RFE were as follows: $r(8)=$ $.53, p>.05$, for the ccw condition, and $r(8)=.73, p<.05$, for the cw condition. The correlations between the righting effect and the inner frame settings were $r(8)=.63$, $p<.05$, for the ccw condition, and $r(8)=$ $.57, p<.05$, for the cw condition. The correlations between the inner frame settings and the RFE were $r(8)=.68, p<.05$, for the ccw condition, and $r(8)=.55, p<.05$, for the cw condition.

\section{Discussion}

It is obvious that an illusion was induced by tilting the outer frame, even though the inner frame was kept upright. The question might be raised as to why the RFE is less than that obtained in Experiment 1 (where it was approximately $10^{\circ}$ ), even though both experiments employed the same visual angle of $54^{\circ}$ for the outer frame. First, it must be recalled that in the previous experiment the visual angle of outer frame and rod were the same, whereas in this experiment the rod subtended a visual angle of approximately $32^{\circ}$ in contrast to the $54^{\circ}$ of the outer frame. Second, when the RFE is measured in this experiment, there is the additional presence of an inner frame. The observer is presented with a more complex configuration and a more difficult task. Third, there is the possibility that the upright inner frame might lessen the righting effect of the outer frame, thereby resulting in a smaller RFE.

\section{Subsidiary Experiment With Head Tilted}

This experiment was replicated using 10 different observers of both sexes; the observer's head was tilted $45^{\circ} \mathrm{cw}$. In all other respects the conditions of the preceding experiment obtained. We reasoned that by weakening available gravity cues, the observer would become more dependent upon the visual field, with the result that a larger RFE would be found. The results show that the RFE increased significantly only in the cw condition $\left(M=11.3^{\circ}\right), t(22)=2.68, p<$ .05 . The mean effect for the ccw-condition RFE was $8.4^{\circ}$. The righting effect for the outer frame increased significantly in the ccw condition to $16^{\circ}, t(22)=3.48, p<.01$; and in the clockwise condition to $18.6^{\circ}$, $t(22)=8.73, p<.001$. The increased effect on the inner frame of $12.4^{\circ}$ in the ccw condition was significant, $t(22)=2.29, p<.05$, whereas the effect of $13.1^{\circ}$ in the cw condition was not.

\section{Control Experiment: Rod Alone}

As a further control for the head-tilt experiments described, an experiment was performed using a rod alone in an erect and head-tilt condition. Ten new observers of both sexes were used. It was also deemed desirable to ascertain whether the delay condition that was used throughout in any way affected the veridical perception of a rod, and so this condition was compared with an immediate condition. Each observer was therefore given one trial in each of these four conditions, with order of trials counterbalanced across observers. We found that the observers were accurate in the erect and $45^{\circ}$ 
head tilt conditions, in the immediate condition, and in the delay condition (see Table 2). That is, whether the observer's head was upright or tilted, the observer had little difficulty in adjusting a rod to the vertical in the absence of a surrounding frame.

In light of this last experiment, it appears all the more implausible to attempt to explain the enhanced results of the head-tilt experiments in terms of any A-effect. It is apparent that the increased RFE arises out of an increased reliance upon the visual field, which is comprised of the frame surrounding the rod. Thus, the head-tilt experiments lend further credence to the hypothesis that the RFE is a function of the righting of the frame.

\section{General Discussion}

Given the hypothesis that the RFE is a function of the amount of underestimation of frame tilt, it might be asked why the mean RFE does not equal the mean degree of righting in each experiment. To answer this question it is necessary to consider further the nature of the task given to the observer. The observer is required to adjust a tilted frame to the upright. If the frame is tilted by $20^{\circ}$ and the observer perceives it as tilted by only $8^{\circ}$, then the degree of righting will be equal to $12^{\circ}$. What if the frame were initially tilted by $8^{\circ}$ ? Would the observer perceive it as vertical? Not necessarily, because the $12^{\circ}$ of righting was for a $20^{\circ}$-tilted frame. Since the task entails judging a frame whose orientation is in a process of continual change, it is not likely that the observer will adjust the frame precisely to the tilt initially perceived. By virtue of the nature of the righting task, therefore, we do not believe that it is unreasonable to expect the mean RFE to differ somewhat from the mean degree of righting.

In other words, our frame-adjustment task does not yield a precise measure of the degree of perceptual righting of the frame in its initially tilted position, and that is the value that should most precisely correspond to the RFE according to our hypothesis. Still, it certainly is the case that our frameadjustment task would yield values highly correlated with the righting that occurred for each subject in viewing the frame in its initially tilted position. Thus, for example, a subject prone to righting would tend to perceive the frame as almost upright in its initial position and would, therefore, accept it as upright in a position at or close to its starting orientation.

Earlier we described the righting task employed here as reducing to a predicted effect of starting position. That should not be interpreted in terms of typical effects of this kind associated with psychophysical procedures such as the method of adjustment or limits. First of all, effects of the latter kind are small in relation to the magnitude of the effects we were predicting and that were obtained. Moreover, the spread between $\mathrm{cw}$ and ccw starting positions of the rod in the RFE task, which would also reflect such a starting-position effect, was negligible. Finally, in the control experiment, in which only the rod was judged, there was no evidence of any starting-position effect. Thus the strong effect in the frame-adjustment task clearly reflected something about how the frame is perceived and is not simply a bias of measurement procedure.

In the introduction to Experiment 2, we argued that induced movement might provide a useful analogue for the rod-and-frame effect. In fact, a recent study by Rock, Auster, Schiffman, and Wheeler (1980) has demonstrated that when induced movement occurs at rates at which the rectangle exceeds the subject-relative threshold, the moving rectangle is perceived as stationary or as moving less than it actually is. Rock et al. proposed that induced movement is the solution to a problem in which the observer is faced with a conflict between information derived from object-relative displacement and subject-relative displacement.

In the present study, we found that the frame was consistently perceived as being phenomenally upright, or as less tilted than it was. This righting or underestimation of frame tilt in the RFE parallels the underestimation of perceived movement of the rectangle reported in the induced movement study. Further, in that study the perceived movement of the stationary spot was found 
to be the result of a process in which movement was subtracted from the rectangle and attributed to the spot. This is consistent with the present finding that the RFE is a direct function of the underestimation of the frame's tilt.

We found that the RFE could be manipulated through the use of a double frame apparatus. When the outer frame was kept upright while the inner frame was tilted, the RFE was eliminated. When the outer frame was tilted and the inner frame kept upright, the RFE was induced. Similar results have been reported by Brosgole (1968) and Farber (Note 1), who have demonstrated that the induced movement of the spot is a function of its relation to the outermost frame in the induced movement paradigm. With the outermost frame stationary, no induced movement occurred. This is understandable because one can hardly expect motion of the innermost frame to be underestimated under such conditions. But when the outermost frame moves, induced movement of the spot (and innermost frame) occurs. This is understandable because here, the motion of the outer frame can be underestimated.

It has been suggested that in induced movement, the observer who is actually fixating the stationary spot feels or interprets his or her eyes to be tracking the phenomenally moving spot. Also, a stationary spot that is placed in front of a moving frame surrounding the observer is perceived to be moving in the same direction as the observer feels himself or herself to be moving. Here we have conditions that satisfy both induced movement of the object and of the self. These facts are of interest in light of the phenomenon of induced head tilt reported in the RFE (Ebenholtz \& Benzschawel, 1977; Sigman et al., 1978, 1979). It has been suggested that induced head tilt is capable of explaining at least part of the RFE. We believe that induced head tilt is the result of visual capture much like the type that occurs when an observer interprets that his or her eyes are tracking the phenomenally moving spot or interprets himself or herself to be in motion as in the cases mentioned above. In the RFE the observer may experience both a tilting of the rod and of his or her head or body, in a direction opposite to the tilt of the frame. Thus, it would seem to be begging the question to attempt to explain the RFE in terms of induced head tilt, since such felt head tilt is probably the result of underestimating the tilt of the surrounding frame, as is the case with the RFE.

A problem-solving theory appears to be capable of explaining the results found in our study. We propose that the perceptual system has certain preferences or makes certain assumptions regarding stimulus relationships. First, the perceptual system assumes that a large, tilted frame of reference is upright, or is less tilted than it is. Second, the perceptual system will detect the angular relation of one thing to another, such as of a rod to a frame. Thus, if a frame that is tilted appears upright, a vertical rod within it must appear tilted in the opposite direction and by the same amount as the tilt of the frame. If a frame that is tilted appears less tilted, then a vertical rod within it will appear somewhat tilted in the opposite direction. This concomitant perceived orientation of the rod and frame is based on the misperception of the orientation of the framethe righting effect. It is as if the perceptual system adds to the orientation of the rod the angle subtracted from the perceived orientation of the frame. To nullify the apparent tilt of a vertical rod, the observer then rotates it in the direction of the frame by an amount equal to the degree of righting of the frame. Thus, the RFE can be seen as representing a rational solution to a problem.

It is worth mentioning that in the tiltedhead experiments, there were numerous instances where the frame was accepted as completely upright in its initial position. Along with this complete righting was a correspondingly large rod-and-frame effect. We have already argued that these effects are not likely to be the result of an A-effect, since adequate steps were taken to eliminate or control for it.

We have presented evidence supporting our argument that the larger the frame, the more likely it is that it will serve effectively as a surrogate of the visual axes of space. Others may say that the effectiveness of a large frame is simply a direct function of the 
degree of its retinal eccentricity, since it has been demonstrated that it is visual angle rather than phenomenal size that determines the potency of the frame (Ebenholtz, 1977; Ebenholtz \& Callan, 1980). This interpretation would seem to be consistent with other evidence bearing on the efficacy of the periphery of the retina in determining spatial attributes of perception such as perceived self-motion (Ebenholtz \& Callan, 1980; Held, 1970; Held, Dichgans, \& Bauer, 1975; Leibowitz \& Post, in press). However, there is no necessary contradiction between these two interpretations, since it is plausible to suppose that a frame will be effectual as a world surrogate to the extent that it "surrounds" the observer. Such surroundedness would be a function of visual angle rather than perceived size. Therefore the effectiveness of a frame will ordinarily be correlated with the degree of retinal eccentricity. Still it may be possible to separate experimentally retinal locus from perceived surroundedness.

\section{Reference Note}

1. Farber, J. M. Peripheral dominance in dual-surround induced motion. Paper presented at the meeting of the Eastern Psychological Association, Philadelphia, April 1979.

\section{References}

Asch, S. E., \& Witkin, H. A. Studies in space orientation: I. Perception of the upright with displaced visual fields. Journal of Experimental Psychology, 1948, 38, 325-337. (a)

Asch, S. E., \& Witkin, H. A. Studies in space orientation: II. Perception of the upright with displaced visual fields and with body tilted: Journal of Experimental Psychology, 1948, 38, 455-477. (b)

Aubert, H. Eine scheibare bedeutende Drehung von Objekten bei Neigung des Koppes nach rechts odor links. Virchows Archives, 1861, 20, 381-393.

Bauermeister, M. Effect of body tilt on apparent verticality, apparent body position, and their relation. Journal of Experimental Psychology, 1964, 67, 142147.

Bauermeister, M. Differences between right versus left lateral body tilt in its effect on the visual and tactual perception of verticality. Psychological Research, 1978, 40, 183-187.

Beh, H. C., Wenderoth, P. M., \& Purcell, A. T. The angular function of a rod-and-frame illusion. Perception \& Psychophysics, 1971, 9, 353-355.

Békésy, G. von. Sensory inhibition. Princeton, N.J.: Princeton University Press, 1967.
Blakemore, C., Carpenter, R. H. S., \& Georgeson, M. A. Lateral inhibition between orientation detectors in the human visual system. Nature, 1970, 228 , 37-39.

Brosgole, L. Analysis of induced motion. Acta Psychologica, 1968, 28, 1-44.

Carpenter, R. H. S., \& Blakemore, C. Interactions between orientations in human vision. Experimental Brain Research, 1973, 18, 287-303.

Duncker, H. Über induzierte Bewengung. Psychologische Forschung, 1929, 12, 180-259. (Translated and condensed in W. Ellis, Ed., Source book of Gestalt psychology. New York: Humanities Press, 1950.)

Ebenholtz, S. M. Determinants of the rod and frame effect: The role of retinal size. Perception \& Psychophysics, 1977, 22, 531-538.

Ebenholtz, S. M., \& Benzschawel, T. L. The rod and frame effect and induced head tilt as a function of observation distance. Perception \& Psychophysics, $1977,22,491-496$.

Ebenholtz, S. M., \& Callan, J. W. Modulation of the rod and frame effect: Retinal angle vs. apparent size. Psychological Research, 1980, 42, 327-334.

Gogel, W. C., \& Newton, R. E. Depth adjacency and the rod and frame illusion. Perception \& Psychophysics, 1975, 18, 163-171.

Goodenough, D. R., Oltman, P. K., Sigman, E., Rosso, J., \& Mertz, H. Orientation contrast effects in the rod and frame test. Perception \& Psychophysics, $1979,25,419-424$.

Goodenough, D. R., Sigman, E., Oltman, P. K., Rosso, J., \& Mertz, H. Eye torsion in response to a tilted visual stimulus. Vision Research, 1979, 19, 11771179.

Held, $R$. Two modes of processing spatially distributed visual stimulation. In F. O. Schmidt (Ed.), The neurosciences: Second study program. New York: Rockefeller University Press, 1970.

Held, R., Dichgans, J., \& Bauer, J. Characteristics of moving visual scenes influencing spatial orientation. Vision Research, 1975, 15, 357-365.

Hughes, P. C. The influence of the visual field upon the visual vertical in relation to ocular torsion of the eye (Doctoral dissertation, University of Oklahoma, 1973). Dissertation Abstracts International, 1973, 33, 468B. (University Microfilms No. 73-91,58B)

Koffka, K. Principles of Gestalt psychology. New York: Harcourt, Brace, 1935.

Leibowitz, H. W., \& Post, R. B. The two modes of processing concept and some implications. In J. J. Beck (Ed.), Organization and representatlon in perception. Hillsdale, N.J.: Erlbaum, in press.

Müller, G. E. Úber das Aubertsche Phanomenon. Zeitschrift für Psychologie und Physlologie der Sinnesorgane, 1916, 49, 109-244.

Rock, I., Auster, M., Schiffman, M., \& Wheeler, D. Induced movement based on subtraction of motion from the inducing object. Journal of Experimental Psychology: Human Perception and Performance, $1980,6,391-403$.

Sigman, E., Goodenough, D. R., \& Flannagan, M. Subjective estimates of body tilt and the rod-and-frame 
test. Perceptual and Motor Skills, 1978, 47, 10511056.

Sigman, E., Goodenough, D. R., \& Flannagan, M. Instructions, illusory self-tilt, and the rod-and-frame test. Quarterly Journal of Experimental Psychology, $1979,31,155-165$.

Templeton, W. B. Visual normalization: The method of kinesthetic matching. Perception \& Psychophysics, $1972,12,422-424$.

Wenderoth, P. M. The distinction between the rod and frame illusion and the rod and frame test. Perception, 1974, 3, 205-212.

Witkin, H. A. Perception of body position and of the position of the visual field. Psychological Monographs, 1949, 63(7, Whole No. 302).

Witkin, H. A., \& Asch, S. E. Studies in space orientation: IV. Further experiments on perception of the upright with displaced visual fields. Journal of Experimental Psychology, 1948, 38, 762-782.

Young, L. R., Oman, C. M., \& Dichgans, J. M. Influence of head orientation on visually induced pitch and roll sensation. Aviation, Space, \& Environmental Medicine, 1975, 46, 264-268.

Received October 23, 1981

\section{Instructions to Authors}

For further information on content, authors should refer to the editorial in the August 1978 issue of the Journal (Vol. 5, No. 3, pp. 355-356). Authors should prepare manuscripts according to the Publication Manual of the American Psychological Association (2nd ed.). Instructions on tables, figures, references, metrics, and typing (all copy must be doublespaced) appear in the Manual. Manuscripts should include an abstract of 100-175 words. Authors are requested to refer to the "Guidelines for Nonsexist Language in APA Journals" (Publication Manual Change Sheet 2, American Psychologist, June 1977, pp. 487-494) before submitting manuscripts to this journal.

APA policy prohibits an author from simultaneously submitting the same manuscript to two or more journals. Authors should submit manuscripts in quadruplicate, and all copies should be clear, readable, and on paper of good quality. Authors should keep a copy of their manuscript to guard against loss. Mail manuscripts to Editor-elect William Epstein, Department of Psychology, University of Wisconsin, W. J. Brogden Psychology Building, 1202 West Johnson Street, Madison, Wisconsin 53706.

Addresses for the editors of the other JEP journals are as follows: Journal of Experimental Psychology: General, Gregory A. Kimble, Department of Psychology, Duke University, Durham, North Carolina 27706 (submit 4 copies of the manuscript); Journal of Experimental Psychology: Learning, Memory, and Cognition, Richard M. Shiffrin, Department of Psychology, Indiana University, Bloomington, Indiana 47405 (submit 4 copies of the manuscript); and Journal of Experimental Psychology: Animal Behavior Processes, Donald S. Blough, Department of Psychology, Brown University, Providence, Rhode Island 02912 (submit 3 copies of the manuscript).

The editors have agreed to use blind review when it is requested by the author. Authors requesting blind review should prepare manuscripts to conceal their identity. 